\title{
Season Impact on the Technical and Physical Training Load in Professional Volleyball
}

\author{
Thiago A.G. Horta* (D), Maurício G. Bara Filho (D), Bernardo Miloski, Daniel G.S. de \\ Freitas and Jeferson M. Vianna
}

Faculty of Physical Education and Sports, Federal University of Juiz de Fora, Brazil

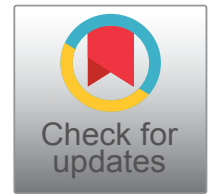

*Corresponding author: Thiago Andrade Goulart Horta, Faculty of Physical Education and Sports, Federal University of Juiz de Fora, Campus Universitario S/N, Martelos, CEP 36036-900, Juiz de Fora-MG, Brazil, Tel: +55-32-98830-0982

\begin{abstract}
Background: The development or maintenance of fitness and the enhancement of biomotor skills are two important components in the preparation of intermittent team sports athletes for the frequent and substantial demands faced in competition. On the other hand, the interpretation of training data contextualized with the period in which the team is in the season, are of extreme importance to avoid negative adaptations, injuries, and illnesses to athletes.
\end{abstract}

Objective: This study aimed to analyze and describe the dynamics of the distribution of strength and technical training load of a professional volleyball team over a competitive season.

Methods: Fourteen male athletes participated in the study. The Training Load (TL) was monitored through the rate of perceived exertion of the session (RPE session) over 33 weeks of a competitive season. The Accumulated TL (ATL), technical training load (TECTL), and Strength Training Load (STL) were calculated for the preparatory period (PP), Competitive Period I (CPI), Competitive Period II (CPII), and Competitive Period III (CPIII). Physical performance was analyzed through the countermovement vertical jump test (CMJ) at three points throughout the season.

Results: ATL was higher in PP and CPI $(p<0.05)$ than in CPII and CPIII. STL was higher in PP $(p<0.05)$ than in CPI, CPII, and CPIII. The TECTL was higher in CPI and CPII $(p<$ 0.05 ) than in CPIII. In the analysis of physical performance, no significant differences $(P>0.05)$ were observed in the $\mathrm{CMJ}$ at the three points analyzed: PP, CPI, and CPII.

Conclusion: The results showed that the period of the season directly impacts the dynamics of the distribution of technical and physical training loads, in which the decrease in ATL was observed in periods of greater competitive demand.

\section{Keywords}

Training load, Session-RPE, Team sports, Periodization, Physical conditioning

\section{Introduction}

The development or maintenance of fitness and the enhancement of biomotor skills are two important components in the preparation of intermittent team sports athletes for the frequent and substantial demands faced in competition [1]. In addition, reducing the likelihood of athlete injuries, illnesses, and maladaptive responses to training involve a complex process of controlling the imposed stimulus (external training load) and monitoring the athletes' physiological response to the stimulus (internal training load) [2]. In order to achieve these goals, training is often organized through seasonal periods within annual planning to match the performance peak with the competition period [3]. In Brazil, elite volleyball teams participate in competitions with long formats of duration [4], in which peak performance must be reached in the short term and for the entire competitive season. This whole process becomes even more complex because specific training sessions for athletes' physical, technical, and tactical development are conducted in an integrated manner [5].

Volleyball is characterized by the performance of intermittent explosive actions, followed by brief periods of recovery between one point and another $[4,6,7]$. The actions consist of short-distance runs performed at high

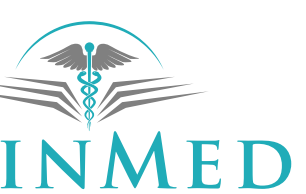

INTERNATIONAL LIBRARY

Citation: Horta TAG, Filho MGB, Miloski B, Freitas DGS, Vianna JM (2021) Season Impact on the Technical and Physical Training Load in Professional Volleyball. Int J Sports Exerc Med 7:183. doi. org/10.23937/2469-5718/1510183

Accepted: February 26, 2021; Published: February 28, 2021

Copyright: (C) 2021 Horta TAG, et al. This is an open-access article distributed under the terms of the Creative Commons Attribution License, which permits unrestricted use, distribution, and reproduction in any medium, provided the original author and source are credited. 
speed, rapid movements in various directions, dives on the court, and successive vertical jumps, all integrated with the execution of specific technical skills of volleyball [4,6-9]. Despite countless factors that can influence an athlete's success, it is essential that athletes have physical, technical, and tactical proficiency for optimal sports performance [5]. In team sports such as volleyball, tactical training seeks to reproduce the reality of the game, working collectively with the development of the team's performance pattern to exploit characteristics of opposing teams, and forms the majority of a teams' daily training routine [7]. In turn, technical training reproduces more specific situations using full or reduced numbers of athletes, with the aim of improving technical skills inherent in the modality (defense, serve, reception, attack, block and setting) or the player's acting position $[5,7]$.

Among a wide variety of sports, well-developed physical abilities are associated with reducing the risk of injury, creating a protective effect for athletes $[10,11]$. Thus, strength training is a fundamental component of training for any high-performance sports team [5]. Especially in modalities with high demands for explosive actions and neuromuscular demand, such as volleyball, the development of strength and power are fundamental components for improving performance as a whole [9]. Therefore, strength training in these teams will extend through almost the entire season to develop and maintain maximum strength and explosive strength of the athletes [12]. The maximization of these responses to strength training are obtained mainly by the direct manipulation of variables involved, such as the selection and order of exercises, recovery interval length between sets, maximum load intensity, and training volume [12].

In this sense, studies have already demonstrated the reliability of the use of subjective methods of perceiving the effort performed, such as the rate of perceived exertion of the session (RPE - session) [13], for monitoring the load in strength training for some time [14]. The simplicity of the method, the ease of use with large groups of athletes, in addition to its economic viability, make it an extremely practical method for programming resistance training for sports teams $[12,15]$. In volleyball, confirmation of the method's validity (RPE session) has already been demonstrated in several studies with the most different approaches in relation to monitoring the training load $[4,6-8,16-20]$. However, most of the aforementioned approaches used global training load analyses, with a unified record of physical, technical, and tactical work performed by athletes in their routines in a single score. Moreover, few studies have described in detail the training load of physical and technical work in professional volleyball teams [19]. The possibility of separately analyzing the different types of training applied to a sports team in a simple and practical way can increase the accuracy in the adequacy of the training load [8]. In addition, the registration of the different workloads applied can be interpreted with results of physical, technical and tactical performance in training and games more accurately. On the other hand, the interpretation of training data contextualized with the period in which the team is in the season, are of extreme importance to avoid negative adaptations, injuries, and illnesses to athletes $[11,18]$. Thus, the aim of the present study was to analyze and describe the dynamics of the distribution of strength and technical training load of a professional volleyball team over a competitive season.

\section{Methods}

\section{Subjects}

The participants were players from a professional volleyball team. In total, 14 male athletes (four hitter spikers, two opposites spikers, two setters, two liberos, and four middle-blockers), with physical characteristics (mean \pm standard deviation) (age: $26.7 \pm 5.5$ years, body mass: $95.8 \pm 8.2 \mathrm{~kg}$, height: $197.0 \pm 7.9 \mathrm{~cm}$, body fat: $14.8 \pm 5.8 \%$ ) were analyzed. No athlete was $<18$-yearsold. The study was approved by the Federal University of Juiz de Fora Human Research Ethics Committee (CER/ UFJF, protocol no. 058207/2014), and all subjects signed a form giving informed consent for their voluntary participation in the study.

\section{Design}

Data were collected over the regular season $(33$ weeks) of a volleyball team, which participated in three major championships. The season consisted of a preparatory period (PP) of 8 weeks duration (weeks 1 to 8 ); a competitive period of 25 weeks, divided into competitive period I (CPI), consisting of 5 weeks (weeks 9 to 13), during which the team played the State Championship and a preparatory tournament in Argentina, competitive period II (CPII), composed of 10 weeks (weeks 14 to 23), in which the team played only the Super League (main national volleyball competition) with the games of the first phase of the competition, and competitive period III (CPIII), composed of 9 weeks (week 25 to 33), in which the team participated in the second Super League classification phase and the Brazil Volleyball Cup. The detailed view of the season's schedule is described in Figure 1. Monitoring of training load (TL) occurred daily 30 minutes after training sessions. All training was planned by the coaching staff and was not influenced by the researchers.

\section{Training description}

In the present study, the morning training routine of the investigated team was analyzed, comprised of physical and technical training. Athletes were usually divided into small groups $(G 1, G 2, G 3)$ based on activities to be performed, or based on the needed development areas of each athlete. Before the first strength or technical 


\begin{tabular}{|c|c|c|c|c|c|c|c|c|c|c|c|c|c|c|c|c|c|c|c|c|c|c|c|c|c|c|c|c|c|c|}
\hline \multicolumn{31}{|c|}{ SEASON TRAINING PROGRAM OVERVIEW } \\
\hline Period & \multicolumn{8}{|c|}{$\begin{array}{l}\text { Preparatory Period } \\
\text { (PP) }\end{array}$} & \multicolumn{4}{|c|}{$\begin{array}{c}\text { Competitive } \\
\text { Period I (CPI) }\end{array}$} & \multicolumn{8}{|c|}{$\begin{array}{l}\text { Competitive Period II } \\
\text { (CPII) }\end{array}$} & R & \multicolumn{9}{|c|}{$\begin{array}{l}\text { Competitive Period III } \\
\text { (CPIII) }\end{array}$} \\
\hline Weeks & 1 & 2 & 3 & 4 & 5 & 6 & 7 & 8 & \begin{tabular}{l|l}
9 & 10
\end{tabular} & 11 & 12 & 13 & 141 & 15 & $16 \mid 1$ & 1718 & $18 \mid 19$ & 20 & 21 & \begin{tabular}{|l|l|l}
22 & 23 \\
2 &
\end{tabular} & $23 \mid 24$ & 425 & 26 & 27 & 28 & 29 & 30 & 31 & 32 & 33 \\
\hline \multirow{2}{*}{ Mesocycle } & \multicolumn{2}{|c|}{\begin{tabular}{|l|} 
I \\
\end{tabular}} & \multicolumn{6}{|c|}{ II } & \multicolumn{2}{|c|}{ III } & \multicolumn{2}{|c|}{ IV } & \multicolumn{5}{|c|}{$\mathrm{V}$} & \multicolumn{3}{|c|}{ VI } & \multicolumn{3}{|c|}{ VII } & \multicolumn{2}{|c|}{ VIII } & \multicolumn{2}{|c|}{$\mathrm{IX}$} & \multicolumn{3}{|c|}{$\mathrm{x}$} \\
\hline & \multicolumn{2}{|c|}{ Adap } & \multicolumn{6}{|c|}{ Intensification } & & & & & \multicolumn{5}{|c|}{ Competition } & \multicolumn{4}{|c|}{ Competition } & \multicolumn{2}{|c|}{ Comp. } & \multicolumn{2}{|c|}{ Comp. } & \multicolumn{2}{|c|}{ Comp. } & \multicolumn{3}{|c|}{ Comp. } \\
\hline Objective (ST) & A & $A$ & & $\mathrm{H}$ & & & MS & & & & & & & & MS/ES/T & & & & ES/ & $\mathrm{V}$ & $\mathrm{R}$ & M & MS & $\mathrm{MS} / \mathrm{E}$ & & MS & & & IS/ES & \\
\hline & & & & & & & & & & treng & th $\mathrm{Tr}_{1}$ & raini & ing $(S$ & (ST) - & - Supe & perset & et Met & thod & & & & & & & & & & & & \\
\hline $\mathrm{N}^{\circ}$ of sessions & 4 & 4 & 6 & 6 & 6 & 6 & 5 & 35 & \begin{tabular}{l|l}
5 & 4
\end{tabular} & 3 & 4 & 2 & 2 & 3. & 43 & \begin{tabular}{l|l}
3 & 4
\end{tabular} & 42 & 4 & 4 & 32 & 20 & 5 & 2 & 2 & 5 & 3 & 3 & 4 & 3 & 2 \\
\hline$N^{\circ}$ of exercises & 1. & 3 & & 14 & & & & & & & 12 & & & & & & 14 & 12 & 14 & 4 & 10 & 10 & 14 & & 12 & & 14 & 12 & 2 & 14 \\
\hline Effort & $3 x$ & 12 & & $x 8-10$ & & & $2-4 \times 4$ & $4-6$ & & $\mathrm{x} 4 \mathrm{v}$ & $4 x^{4}$ & & $4 \times 4 v$ & & $4 \times 4$ & & $4 \mathrm{v}$. & & $4 \times 4$ & $4 \mathrm{v}$. & & $3-4 x$ & $x 6-8 \mid 3$ & $3 \times 6 \mathrm{v}$ & $3 \times 6$ & $3 x^{6}$ & & $3 \times 6$ & $3 \times 6$ & $6 \mathrm{v}$ \\
\hline Rest & $60-$ & $90 \mathrm{~s}$ & & $0-90$ & & & $20-1$ & $180 \mathrm{~s}$ & & $20 \mathrm{~s}$ & 120 & $\mathrm{Os}_{\mathrm{s}}$ & $120 \mathrm{~s}$ & & $120 \mathrm{~s}$ & & $20 \mathrm{~s}$ & & 120 & $20 \mathrm{~s}$ & & & & $20 \mathrm{~s}$ & & & & $120 \mathrm{~s}$ & & \\
\hline Load & & & $0-80^{\circ}$ & & & & $85-90$ & & & $-85 \%$ & $85-9 c$ & $00 \% 6$ & $60-85^{\circ}$ & & $\begin{array}{l}85- \\
90 \%\end{array}$ & & $-85 \%$ & & $0 \%$ v.- & $-85 \%$ & & & $-90 \%$ & & & $90 \% /$ & $60^{\circ}$ & $\%$ v. & & \\
\hline & & & & & & & & & & & & chnic & cal Tr & rainir & ing ( $T$ & IECT & & & & & & & & & & & & & & \\
\hline $\mathrm{N}^{\circ}$ of sessions & 2 & 4 & 3 & 5 & 3 & 3 & 3 & 32 & 22 & 1 & 1 & 3 & 3 & 2 & $\begin{array}{ll}2 & 3 \\
\end{array}$ & \begin{tabular}{l|l}
3 & 4 \\
\end{tabular} & 43 & 3 & 4 & 32 & 20 & 3 & 3 & 3 & 4 & 4 & 3 & 2 & 3 & 3 \\
\hline & & & & & & & & & & & & Gam & mes of & f the & seaso & & & & & & & & & & & & & & & \\
\hline Games & 0 & 0 & 0 & 0 & 0 & 0 & 11 & \begin{tabular}{l|l|}
1 & 1
\end{tabular} & 12 & 1 & 2 & 5 & 2 & 1 & 0 & $\begin{array}{ll}2 & 2 \\
\end{array}$ & 22 & 1 & 2 & \begin{tabular}{l|l}
1 & 2 \\
\end{tabular} & 2 & 1 & 2 & 2 & 0 & 2 & 2 & 2 & 1 & 1 \\
\hline Local Game & & & & & & & $\mathrm{OH} \mathrm{A}$ & & $\mathrm{AHOH}$ & $\mathrm{AH}$. & $\mathrm{AHC}$ & $\mathrm{OH}$ & $\mathrm{OH} \mathrm{O}$ & $\mathrm{OH}$ & & $\mathrm{AO}$ AF & $\mathrm{HAO}$ & $\mathrm{OH}$ & $\mathrm{AHO}$ & $\mathrm{OH} \mathrm{AC}$ & 0 & $\mathrm{OH}$ & AO C & $\mathrm{OH}$ & & & $\mathrm{AO}$ & $\mathrm{AHC}$ & $\mathrm{OH} A$ & $\mathrm{AH}$ \\
\hline Game Type & & & & & & & $\mathrm{SC} S$ & SC sc & SC SC & $\mathrm{SC}$ & IF 1 & IC & SC $\mathrm{s}$ & SL & & SL SL & SL SL & SL & SL S & SL SL & $\mathrm{L}$ & $\mathrm{BC}$ & SL & $\begin{array}{l}\text { SL } \\
\text { BC }\end{array}$ & & & SL & FG & SL $s$ & SL \\
\hline
\end{tabular}

Figure 1: Training program overview during 33 weeks of a season in volleyball.

H: Hypertrophy; A: Adaptation; I: Intensification; T: Transformation; R: Recovery; Realiz: Realization; MS: Maximum strength; ES/V: Explosive strength/velocity; C: Competition; OH: Out of home; AH: At home; SC: State championship; IF: International friendly; IC: International championship; SL: Super league; FG: Friendly game; AO: At and out of home; BC: Brazil's cup.

training session, a standard warm-up was held lasting between 10 and 15 minutes. Thus, the training routine consisted of (a) Physical training: (1) Strength training 4-5 times a week, 60 minutes (hypertrophy, strength, and power, according to periodization) (Figure 1); (2) Circuit training 1-2 times a week, 20 minutes (speed and agility exercises) (Figure 2); (3) Functional training 1-2 times a week specifically for volleyball, 30 minutes, with coordination, core, stabilization, and balance exercises; (b) Technical training: 5-6 times a week, with 75 minutes of duration directed to the development of specific technical skills of volleyball (serve, reception, defense, attack, blocking, and set), in addition to technical conditioning exercises, such as displacements and movements in contact with the ball (Figure 2).

\section{Strength training}

All strength training sessions were performed at a specific weight training gym. The sessions were monitored through the total volume of repetitions [12], session duration in minutes, and subjective perception of effort session (RPE method). Regarding the strength training repetitions total volume (VTST) [12], the number of sets was multiplied by the number of repetitions in each exercise of the session, and the sum of the values of each exercise represented the total volume of each training session. The value of the total volume of each week's session was added, thus obtaining the week VTST. The method used to adjust the work intensities (\% of 1 RM) was the maximum repetition method [12] for each work objective (resistance, hypertrophy, strength, explosive strength). Throughout the strength training season, the athletes performed the training divided into two training sessions $A$ and $B$, with the muscle groups divided into two different cards. In addition to the main format, the athletes performed another format (combined training) simultaneously with exercises complementary to the muscle groups of the day's work (Figure 2). This training method is known as a Superset [21], in which the individual performs an exercise for a specific muscle group and then, in sequence, performs another exercise for the same or a different muscle group.

\section{Technical training}

All technical training sessions were held on the court in the team's training gym. Athletes were divided into small groups in most technical training sessions. The main objective of technical training was to practice the correct individual technique of the fundamentals of volleyball, for later adjustment and adequacy within the systems that collectively constitute different parts of the game. A summary example of the activities carried out in TECT is shown in Figure 2. 


\begin{tabular}{|c|c|c|c|c|c|}
\hline \multicolumn{6}{|c|}{ DESCRIPTION OF ACTIVITIES BY TRAINING PERIODS IN THE SEASON } \\
\hline Training & \multicolumn{2}{|c|}{ Preparatory Period } & \multicolumn{3}{|c|}{ Competitive Period } \\
\hline \multirow{8}{*}{$\begin{array}{l}\text { Strength } \\
\text { Two } \\
\text { Training } \\
\text { (A-B) }\end{array}$} & \multirow{2}{*}{$\begin{array}{c}\text { (TRAINING }-\mathrm{A}) \\
\text { Bench press } \\
\text { Incline bench press } \\
\text { Incline fly } \\
\text { Shoulder press dumbbells }\end{array}$} & \multirow{2}{*}{$\begin{array}{c}\text { (COMBINED TRAINING - A) } \\
\text { Side board* } \\
\text { Abduction machine } \\
\text { Crunch - cross bending* } \\
\text { Shoulder bending }\end{array}$} & \multicolumn{2}{|c|}{\begin{tabular}{c|} 
(TRAIINING $-\mathrm{A})$ \\
Pull up open fixed bar Open row
\end{tabular}} & \multirow{2}{*}{\begin{tabular}{l} 
(COMBINED TRAINING - A) \\
Cross bending* \\
Front board* \\
\cline { 1 - 2 } Jump + attack pass \\
Lhoulder bending*
\end{tabular}} \\
\hline & & & $\begin{array}{c}\text { seated } \\
\text { Squat } \\
\text { Throw 1st phase }\end{array}$ & & \\
\hline & \multirow{2}{*}{$\begin{array}{l}\text { Leg press } \\
\text { Half squat bar } \\
\text { Leg extension }\end{array}$} & \multirow{2}{*}{$\begin{array}{l}\text { Pulley triceps } \\
\text { Internal rotation } \\
\text { Shoulder depression }\end{array}$} & \multirow{2}{*}{\multicolumn{2}{|c|}{$\begin{array}{l}\text { EZ curl bar } \\
\text { Leg extension }\end{array}$}} & \multirow{2}{*}{$\begin{array}{c}\text { Shoulder depression + internal } \\
\text { rotation } \# \\
\text { Adduction machine } \#\end{array}$} \\
\hline & & & & & \\
\hline & \multirow{4}{*}{$\begin{array}{l}\text { (TRAINING - B) } \\
\text { Pull up open fixed bar } \\
\text { Open row seated } \\
\text { Frontal Lat pull down } \\
\text { Leg } 45^{\circ} \\
\text { Leg curl machine } \\
\text { Calf machine } \\
\text { Aduction machine }\end{array}$} & \multirow{4}{*}{$\begin{array}{c}\text { (COMBINED TRAINING - B) } \\
\text { Front board* } \\
\text { Jackknife sit-ups* } \\
\text { Trunk flexion sit-ups* } \\
\text { Shoulder extension } \\
\text { rset } \\
\text { Shoulder projection } \\
\text { External rotation } \\
\text { EZ curl bar }\end{array}$} & \multirow{4}{*}{\multicolumn{2}{|c|}{$\begin{array}{l}\text { (TRAINING - B) } \\
\text { Bench press } \\
\text { Incline bench press } \\
\text { Complete shoulder pres } \\
\text { Leg } 45^{\circ} \\
\text { Leg curl machine } \\
\text { Pulley triceps }\end{array}$}} & $\begin{array}{c}\text { (COMBINED TRAINING - B) } \\
\text { Unilateral down launch } \\
\text { Jackknife sit-ups* } \\
\text { Projection + external rotation }\end{array}$ \\
\hline & & & & & sset Shoulder extension\# \\
\hline & & & & & \multirow{2}{*}{ Abduction/Aduction Machine } \\
\hline & & & & & \\
\hline haracteristics & $3 \times 10$ (Hypertrophy goal) & $3 \times 12$ (*20 rep.) & \multicolumn{2}{|c|}{$4 \times 4$ (Strength + Power goal) } & $4 \times 4$ (*20 rep., \#12 rep.) \\
\hline Circuit & \multicolumn{2}{|c|}{$\begin{array}{c}\text { (RESISTANCE CIRCUIT) } \\
\text { Agility staircase - } 1 \text { foot on each step } \\
\text { Shift front - back with squat } \\
\text { Cross-front displacement - change direction } \\
\text { Displacement block - two sides } \\
\text { Defense displacement - crossed past } \\
\text { Front shift - side - back } \Delta \\
\text { Zig-zague + acceleration }\end{array}$} & \multicolumn{3}{|c|}{$\begin{array}{l}\text { (ESTABILIZATION CIRCUIT) } \\
\text { Front plate on disc } \\
\text { Side board } \\
\text { Shoulder stabilization - ball board } \\
\text { One-sided for bed elastic jump } \\
\text { Hops on the square } \\
\text { Educational pitch } \\
\text { Diagonal shoulder lift }\end{array}$} \\
\hline Characteristics & \multicolumn{2}{|c|}{ Location: Court $/ 2 \mathrm{sets}$ of $30^{\prime \prime} \mathrm{sec} . / 45^{\prime \prime} \mathrm{sec}$. Recovery } & \multicolumn{3}{|c|}{ Location: Court / Before Tactical Training / 2 sets of $30 " \mathrm{sec} . / 45^{\prime \prime}$} \\
\hline Technical & \multicolumn{2}{|c|}{$\begin{array}{c}\text { (TECHNICAL EXERCISES - BASIC DEVELOPMENT) } \\
\text { Technical fundamentals of volleyball } \\
\text { Defense training } \\
\text { Blocking technique } \\
\text { Serve training } \\
\text { Reception training } \\
\text { Setting training }\end{array}$} & \multicolumn{3}{|c|}{$\begin{array}{c}\text { (TECHNICAL EXERCISES - OPPONENTS ADJUSTMENTS) } \\
\text { Specific situations for each game } \\
\text { Defense training } \\
\text { Technical-tactical blocking adjustments } \\
\text { Technical-tactical serve targeting } \\
\text { Reception training } \\
\text { Technical-tactical setting training }\end{array}$} \\
\hline Characteristics & \multicolumn{2}{|c|}{ Small group training: game position / game situation / 5-6x week } & \multicolumn{3}{|c|}{ Small group training: game position / game situation / 5-6x week } \\
\hline
\end{tabular}

Figure 2: Example of activities undertaken in different periods of the season.

\section{Training load}

TL was measured daily using the RPE session method [11], which had already been used with similar samples from professional volleyball players $[4,18,20]$. Approximately 30 minutes after the end of each training session, the athletes answered the question "How was your training?" The intensity was measured using the 10-point Borg scale (CR-10) [22] which ranged from 0 (rest) to 10 (maximum effort). The athletes were familiarized with the scale at the beginning of the season, and responses were collected individually. The session TL was calculated by the product of intensity (perceived effort, based on the CR-10 scale) and volume (total session duration in minutes), generating a value in Arbitrary Units (AU). For each week, the Total Weekly Training Load (TWTL), the sum of all training sessions for the week, was calculated for the Accumulated Training Load (ATL) (technical training + strength training), technical training load (TECTL), and Strength Training Load (STL). The TWTL was classified according to the interquartile ranges shown over 33 weeks and categorized as follows:
$<25 \%=$ low $; 25-50 \%=$ moderate-low $; 50-75 \%=$ moder ate-high and $>75 \%=$ high [23].

\section{Physical test}

To assess neuromuscular power, the vertical countermovement jump test (CMJ) was used without the aid of arms. The athletes were instructed to keep their hands positioned on their hips during the execution of the three maximum jump attempts according to the test guidelines. Three test batteries were carried out at different times of the season: Test 1 (beginning of the training season); test 2 (start of the state championship) and test 3 (start of the super league, main competition of the season).

\section{Statistical analysis}

Data are presented as mean \pm standard deviation. The assumptions of normality and homoscedasticity of the data were evaluated using the Shapiro-Wilk test and Levene test, respectively. Once the parametric assumptions were met $(p<0.05)$, one-way ANOVA and Bonfer- 


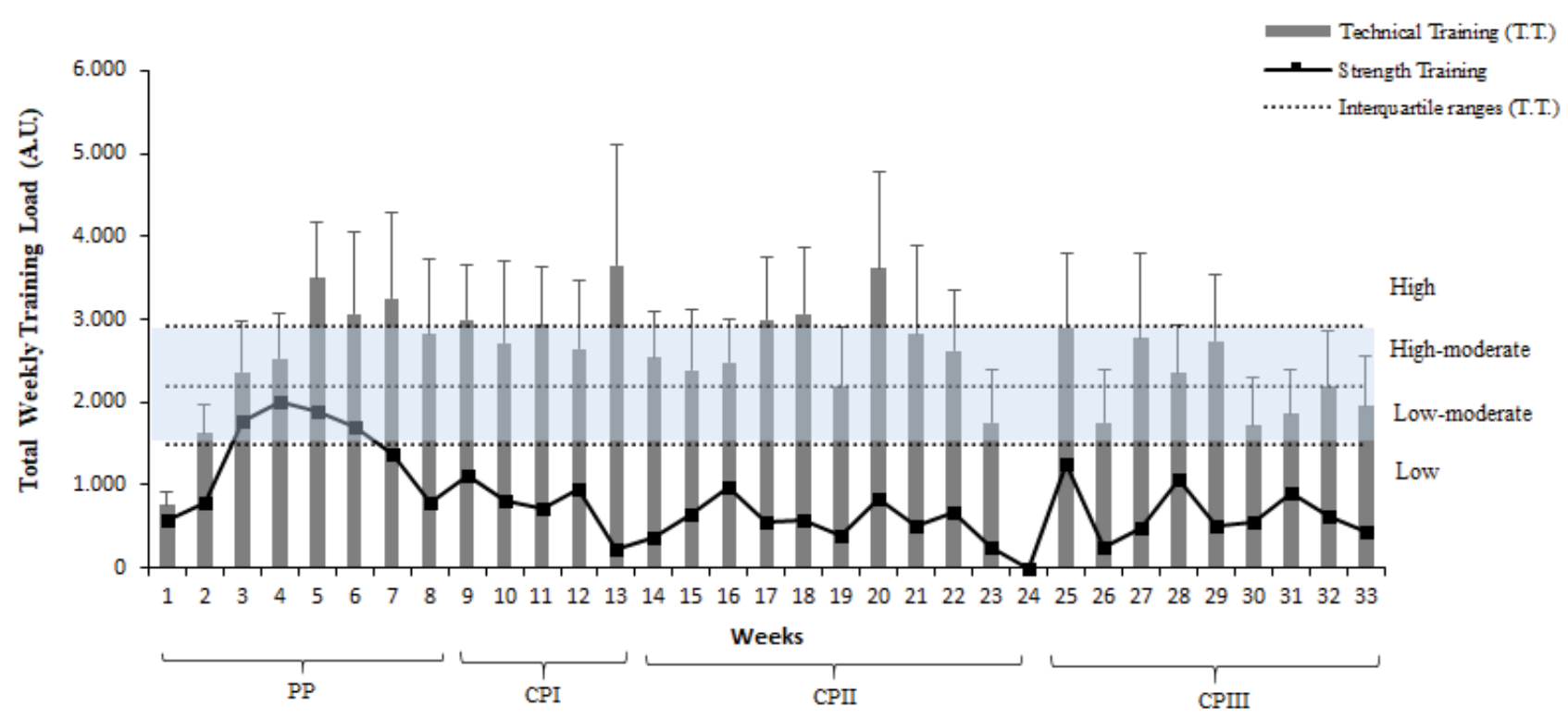

Figure 3: Description of technical and strength training Total Weekly Training Load (TWTL) during 33 weeks of a season in volleyball.

AU: Arbitrary Units. Values presented in mean \pm SD.

roni correction were tested to evaluate for differences between the average Accumulated Training Load (ATL), Technical Training Load (TECTL), Strength Training Load $(\mathrm{STL})$, technical training (RPE), strength training (RPE), technical training volume (TECTV), Strength Training Volume (STV) total strength training volume (VTST) in the four periods analyzed. In the performance analysis using the countermovement vertical jump test (CMJ), repeated measures ANOVA was used to compare the averages between the analyzed periods. The data were analyzed using SPSS v. 25 (SPSS ${ }^{\circledR}$ Inc., Chicago, IL), with a significance level of $p<0.05$.

\section{Results}

Regarding the strength training total volume (VTST), the highest volumes were applied in the PP (week 3: 3168; week 4: 2898; week 5: 2898 and week 6: 2628 repetitions). The strength training intensity shown by athletes, measured through the subjective perception of effort (RPE), ranged between 5.1 (week 4) and 2.6 (week 13). The strength training average PSE throughout the season was 3.7, classified between "Moderate" to "Little difficult" by the CR 10 scale.

Figure 3 shows the weekly distribution of technical (TECTL) and Strength Training Load (STL) during the 33 analyzed weeks of the volleyball season. Over the entire competitive period, TLs ranged from moderate-low to high, with the vast majority of these weeks positioned in the final moment of the season in CPIII. Regarding strength training, during PP, players had the highest training loads presented throughout the season (weeks $3,4,5$, and 6 ). In the competitive period, the vast majority of strength TLs were the low classification ranges. In week 24 , the training load was zero, in which competitions and training were interrupted due to the year-end celebrations in the country.

Finally, Table 1 shows the average values of the Accumulated Training Load (ATL), technical training load (TECTL), Strength Training Load (STL), volume of strength training (STV), volume of technical training (TECV), total volume of strength training (TVST), and the values of vertical jump tests with countermovement (CMJ) at different periods of the season.

\section{Discussion}

The aim of the present study was to analyze and describe the dynamics of the distribution of strength and technical training load of a professional volleyball team over a competitive season. The results showed that ATL was higher in PP and CPI than in CPII and CPIII. Similar results were demonstrated with professional volleyball teams participating in the same Brazil national competition $[4,16,18]$. This distribution of training loads confirmed the programming team analyzed, since the main competition of the season accounted for the Super League started in PCII. Thus, both the PP and PCl were part of the team development process in general, as shown in the description of the mesocycles (Figure 1).

Regarding the Strength Training Load (STL) and the Strength Training Total Volume (STTV), a significant difference was observed with higher values presented in the PP in relation to the competitive periods. In the preparatory period, teams usually seek the general development of athletes with a strong focus on intensifying strength training [24]. Strength training in the PP aimed to adapt athletes in the first weeks to later development in the hypertrophy and maximum strength blocks [24,25] (Figure 1). In the competitive periods of the season, strength training followed a model similar 
Table 1: Training load and vertical jump variables in the four periods of the season.

\begin{tabular}{|c|c|c|c|c|c|}
\hline Variables & Preparatory & Competitive I & Competitive II & Competitive III & TOTAL \\
\hline $\mathrm{N}^{\circ}$ of weeks & 8 & 5 & 10 & 9 & 32 \\
\hline $\mathrm{N}^{\circ}$ of games & 2 & 11 & 15 & 13 & 41 \\
\hline ATL (AU) & $3789 \pm 1638$ & $3676 \pm 1083^{\#}$ & $3180 \pm 1105^{*}$ & $2893 \pm 1074^{*}$ & $3332 \pm 1297$ \\
\hline TECTL (AU) & $2413 \pm 1131$ & $2868 \pm 1062^{* \#}$ & $2613 \pm 952^{\#}$ & $2154 \pm 878$ & $2468 \pm 1023$ \\
\hline STL (AU) & $1338 \pm 672$ & $771 \pm 341^{* \$}$ & $581 \pm 243^{*}$ & $680 \pm 342^{*}$ & $820 \pm 516$ \\
\hline RPE - TECT & $4.0 \pm 0.3$ & $3.9 \pm 0.2$ & $3.8 \pm 0.5$ & $3.4 \pm 0.3^{\star}$ & $3.7 \pm 0.4$ \\
\hline RPE - ST & $4.3 \pm 0.6$ & $3.5 \pm 0.6$ & $3.4 \pm 0.5^{\star}$ & $3.7 \pm 0.3$ & $3.7 \pm 0.6$ \\
\hline V. (min) - TECT & $76 \pm 8^{\#}$ & $95 \pm 9^{* \# \$}$ & $75 \pm 11^{\#}$ & $61 \pm 10^{\star \$}$ & $74 \pm 14$ \\
\hline V. $(\min )-S T$ & $57 \pm 6$ & $56 \pm 7$ & $55 \pm 6$ & $59 \pm 2$ & $57 \pm 5$ \\
\hline VTST (repetition) & $2010 \pm 1061$ & $832 \pm 343^{*}$ & $1039 \pm 358^{*}$ & $1025 \pm 452^{*}$ & $1246 \pm 752$ \\
\hline$\%$ TECTL of ATL & $64 \%$ & $78 \%$ & $82 \%$ & $74 \%$ & $75 \%$ \\
\hline$\%$ STL of ATL & $36 \%$ & $22 \%$ & $18 \%$ & $26 \%$ & $25 \%$ \\
\hline $\mathrm{CMJ}(\mathrm{cm})$ & $43.2 \pm 7.0$ & $43.1 \pm 6.2$ & $44.2 \pm 6.3$ & ----------- & $43.5 \pm 0.6$ \\
\hline
\end{tabular}

Average values \pm standard deviation.

ATL: Accumulated Training Load; AU: Arbitrary Units; TECTL: Technical training load; RPE: Perceived exertion; TECT: Technical training; V (Min): Volume in minutes; STL: Strength Training Load; ST: Strength Training; VTST: Strength training total volume by repetitions; CMJ: Vertical countermovement jump.

"Significant difference (ANOVA repeated measures) for the preparatory period; "Significant difference (ANOVA repeated measures) for competitive period III; ${ }^{\$}$ Significant difference (ANOVA repeated measures) for competitive period II.

to Wave Periodization (WP), with predominance and alternation of maximum strength, explosive strength, and strength speed between weeks and training sessions [24]. Factors such as training logistics, training days between games, distance, and number of trips, in addition to the opponent's level, are decisive for targeting the training stimuli of the sessions [18,20]. Horta, et al. [4] with a professional volleyball team, demonstrated that the training loads of congested weeks with two games in the Super League were significantly lower than those of weeks without games or with just one game. The game itself represents an important impact factor in the organization of training stimuli in their general aspects (physical, technical, and tactical) in the weeks of the season $[4,11]$. In the present study, in some weeks of the competitive period (weeks: 10, 13, 14, 27), the team played two games away from home, and in several others the team played a game at home and traveled to another game away from home (weeks: 17, 19, 23, 26, 29, 30) (Figure 1).

In most team sports the main objective of strength training for athletes is to improve the ability to apply maximum explosive force [24], specially volleyball athletes in the execution of the game's determining actions [7]. However, the literature indicates that no method used in isolation can achieve the range of adaptations necessary for the full development of strength and characteristics related to force-time [24]. Methods of training exercises with body weight, isolated exercises, plyometric exercises, weightlifting, unilateral exercises, and kettlebell training can limit the potential for improvement in the production of maximum strength, but they are relevant in the development of force related to the characteristics of force-time with different demands of motor actions [24]. In addition, the organization's strength training structure can interfere with the expected results. Weakley, et al. [21] demonstrated with rugby union athletes that, in addition to the considerably shorter total running time, greater internal load manifestation (perceived effort), and greater efficiency (average number of kgs lifted per minute) of the combined methods (superset and tri-set) in relation to the traditional method, the combined protocols did not affect the acute neuromuscular function tested by the CMJ test immediately after performing the series of exercises.

The TECTL showed significant differences between the measured periods, with the highest value during CPI and the lowest value during CPIII, in which the team participated in the second phase (return) of the Volleyball Super League. In the four periods of the season, only in the PP did TECTL represent less than $70 \%$ of the total work (ATL) of the team in relation to morning training (Technical and Physical). In the first phase of the season (PP), technical work had the objective of technical reconditioning of main volleyball fundamentals. With the advance of the season for competitive periods, technical training was almost completely adjusted and adapted to the game of tactical situations according to the opponent's characteristics. Some studies in volleyball have shown that technical training has a lower psychophysiological demand than tactical training $[8,26]$. Bara Filho, et al. [17] identified that professional volleyball players maintained heart rates (HR) around $35.8 \%$ of the general training in zone 2 (60-70\% of maximum HR), while Gabbett, et al. [26] demonstrated with junior athletes of Australian volleyball that most of the time (57.4\%) in the most analytical technical training athletes maintained 
heart rates at very low intensities $(40-70 \%$ of the maximum HR). Duarte, et al. [8] investigated a professional volleyball team identified a negative correlation of moderate magnitude for general technical training between the methods (TRIMP-FC $\times$ RPE), reinforcing the usefulness of using RPE in technical training sessions.

Studies in volleyball with professional teams describing the TWTL, with all types of training inserted in the load values (physical, technical, and tactical), report similar average TWTL values for the season: Debien, et al. [18] (3.733 $\pm 1.228 \mathrm{AU})$, and Horta, et al. [20] (3.206 $\pm 685 \mathrm{AU})$. Andrade, et al. [16] identified TWTL values of $(3.512 \pm 876 \mathrm{AU})$ in the PP $(2.843 \pm 1.026 \mathrm{AU})$ in the $\mathrm{CPI}$ and $(2.696 \pm 933 \mathrm{AU})$ in the CPII. Values ranging from 4.000 to $6.000 \mathrm{AU}$ of TWTL have been reported in several studies with professional volleyball teams in PP $[4,6,18]$. Interestingly, the average ATL value (technical + strength training) in the present study $(3.332 \pm 1.297$ $\mathrm{AU})$, which did not include the tactical training load, was very similar to the TWTL values of the mentioned studies. In the present study despite RPE being the same, the volume of technical training was substantially higher than strength training (Table 1). Similar dynamics was demonstrated by Faria, et al. [19] in the training routine of a professional volleyball team.

Monitoring the development of jumping ability in volleyball is essential for understanding the process of adapting to training [9]. In our study, no significant changes were observed in the height of the vertical countermovement jump [27] in the three periods analyzed (PP/CPI/CPII), which comprised a period of 14 weeks of training until the beginning of the CPII. Horta, et al. [6] with professional volleyball athletes no found significant changes in the CMJ during the 6-week preparatory period, as well as Freitas, et al. [28] with adult volleyball athletes in 4 weeks of TL intensification in the pre-competitive period. On the other hand, Debien, et al. [18] observed significant improvements in the CMJ after the $5^{\text {th }}, 16^{\text {th }}$ and $31^{\text {st }}$ weeks of training in the season with professional volleyball athletes. In a more longitudinal investigation, Sheppard, et al. [9] identified significant improvements in the vertical CMJ, deep jump, and jump pass in the Australian volleyball team after 2 years of monitoring. The literature shows significant improvements in strength and power capacity for strength training in periods of up to 4-5 weeks [24]. In the present study, the period comprised the highest values of STL, TECTL and ATL, which may have contributed to the maintenance of the $\mathrm{CMJ}$ values.

This study had some limitations. First, the evolution of the force dynamics related to the strength training performed at different periods of the season was not presented. In addition, the lack of other tests to assess physical performance, such as displacement speed, agility, and upper limb power, could provide additional information on the dynamics of applied loads. Another point was the lack of assessment of the technical development team. Currently in high-performance, teams use performance analysis software that can bring statistical game information related to the efficiency and effectiveness of some fundamentals and technical situations of volleyball, which are routinely trained in technical training sessions.

\section{Practical Applications}

The achievement of high levels of sports performance is due to the proper application of a complex training process, which should promote the development of aspects related to physical, technical, tactical, and mental fitness, simultaneously and in an integrated manner [29]. The present investigation reinforces the results of previous studies $[4,6,19,24]$ by demonstrating the use of high training loads aimed at the development of physical fitness during the preparatory period and during weeks with fewer games in high-performance team sports, represented by the strength training load distribution curve. In addition, the present study also demonstrates that training sessions aimed at developing the technique come to represent a higher percentage of the training load applied during the competition period (vs. preparatory) $[19,23]$. These results, together with previous studies [30], suggest that, in practice, this form of training load organization has been commonly adopted in high-performance team sports during the season.

The study presented demonstrated that it is not necessary to have highly technological and expensive equipment for monitoring the training load. This becomes even more important for the context of lower budget teams, intermediate competitive levels and training categories in volleyball, which can use the resources presented for incorporation in their work. Finally, the results showed that through specific monitoring of the different types of training, the technical committee can interfere more precisely in the distribution of training sessions throughout the season.

\section{Conclusion}

The specific monitoring of each type of training is essential in order to obtain information on the evolution of each component that composes it [15]. The present study aimed to describe the dynamics of training load distribution for two types of training that are fundamental pillars for transfer to tactical training and volleyball games. Finally, conclude that training load values were directly related to the period of the season, in which the decrease in ATL was observed in periods of greater competitive demand. Technical and physical training are reduced in priority to meet the team's tactical training. The results of the present study demonstrated that the method used to monitor training load (RPE session) can be an important tool for the organization and monitoring of technical and strength training in volleyball. 


\section{Acknowledgments}

The authors thank all technical and professional athletes commission staff JF volleyball.

\section{References}

1. McLaren SJ, Macpherson TW, Coutts AJ, Hurst C, Spears IR, et al. (2018) The Relationships Between Internal and External Measures of Training Load and Intensity in Team Sports: A Meta-Analysis. Sports Med 48: 641-658.

2. Bourdon PC, Cardinale M, Murray A, Gastin P, Kellmann M, et al. (2017) Monitoring Athlete Training Loads: Consensus Statement. Int J Sports Physiol Perform 12: S2161-S2170.

3. Fox JL, Stanton R, Sargent C, Wintour SA, Scanlan AT (2018) The Association Between Training Load and Performance in Team Sports: A Systematic Review. Sports Med 48: 2743-2774.

4. Horta TAG, Bara Filho M, Coimbra DR, et al. (2019) Perfil da carga de treinamento no voleibol de alto rendimento: um estudo de caso [Training load profile in high performance volleyball: a case study]. Revista Brasileira de Ciências do Esporte 41: 419-426.

5. Mujika I, Halson S, Burke LM, Balague G, Farrow D (2018) An Integrated, Multifactorial Approach to Periodization for Optimal Performance in Individual and Team Sports. Int J Sports Physiol Perform 13: 538-561.

6. Horta TAG, Bara Filho MG, Coimbra DR, Miranda R, Werneck FZ (2019) Training Load, Physical Performance, Biochemical Markers, and Psychological Stress During a Short Preparatory Period in Brazilian Elite Male Volleyball Players: J Strength Cond Res 33: 3392-3399.

7. Horta TAG, Bara Filho MG, Miranda R, et al. (2017) Influence of vertical jump in the perception of the internal volleyball training load. Rev Bras Med Esporte 3: 403-406.

8. Duarte TS, Alves DL, Coimbra DR, Miloski B, Marins JCB, et al. (2019) Technical and Tactical Training Load in Professional Volleyball Players. Int J Sports PhysiolPerform 14: 1338-1343.

9. Sheppard JM, Newton RU (2012) Long-Term Training Adaptations in Elite Male Volleyball Players. J Strength Cond Res 26: 2180-2184.

10. Gabbett TJ (2016) The training-injury prevention paradox: should athletes be training smarter and harder? Br J Sports Med 50: 273-280.

11. Timoteo TF, Seixas MB, Fernanda M, et al. (2017) Impact of Consecutive Games on Workload, State of Recovery and Well-Being of Professional Volleyball Players 20: 11.

12. Scott BR, Duthie GM, Thornton HR, Dascombe BJ (2016) Training Monitoring for Resistance Exercise: Theory and Applications. Sports Med 46: 687-698.

13. Foster C, Rodriguez-Marroyo JA, de Koning JJ (2017) Monitoring Training Loads: The Past, the Present, and the Future. Int J Sports Physiol Perform 12: S22-S28.

14. Day ML, Mcguigan MR, Brice G, Foster C (2004) Monitoring Exercise Intensity During Resistance Training Using the Session RPE Scale. J Strength Cond Res 18: 353-358.

15. McLaren SJ, Smith A, Spears IR, Weston M (2017) A detailed quantification of differential ratings of perceived exertion during team-sport training. J Sci Med Sport 20: 290295.

16. Andrade DM, Fernandes G, Miranda R, Danilo RC, Filho
B, et al. (2018) Training Load and Recovery in Volleyball During a Competitive Season. J Strength Cond Res 1.

17. Bara Filho MG, Andrade FC de, Nogueira RA, Nakamura FY (2013) Comparisson of different methods of internal load control in volleyball players. Rev Bras Med Esporte 9: 143146.

18. Debien PB, Mancini M, Coimbra DR, Freitas DGS, Miranda $\mathrm{R}$, et al. (2018) Monitoring Training Load, Recovery, and Performance of Brazilian Professional Volleyball Players During a Season. Int J Sports Physiol Perform 13: 11821189.

19. De Faria BSH, Costa Campos YDA, Toledo H, et al. (2020) Comparisson of the training load of professional athletes between modes of volleyball specific drills and strength conditioning. J Phys Educ 31.

20. Horta TAG, Lima PHP de, Matta GG, de Freitas JV, Dias BM, et al. (2020) Training load impact on recovery status in professional volleyball athletes. Rev Bras Med Esporte 26: $158-161$.

21. Weakley JJS, Till K, Read DB, Roe GAB, Darrall-Jones J, et al. (2017) The effects of traditional, superset, and tri-set resistance training structures on perceived intensity and physiological responses. Eur J Appl Physiol 117: 18771889.

22. Foster C, Florhaug JA, Franklin J, Gottschall L, Hrovatin LA, et al. (2001) A New Approach to Monitoring ExerciseTraining. J Strength Cond Res 15: 109-115.

23. Miloski B, Freitas VHD, Nakamura FBY, de A Nogueira FC, Bara-Filho MG (2016) Seasonal Training Load Distribution of Professional Futsal Players: Effects on Physical Fitness, Muscle Damage and Hormonal Status. J Strength Cond Res 30: 1525-1533.

24. Suchomel TJ, Nimphius S, Bellon CR, Stone MH (2018) The Importance of Muscular Strength: Training Considerations. Sports Med 48: 765-785.

25. Hartmann H, Wirth K, Keiner M, et al. (2015) Short-term Periodization Models: Effects on Strength and Speed-strength Performance. Sports Med 45: 1373-1386.

26. Gabbett TJ (2008) Do Skill-Based Conditioning Games Offer a Specific Training Stimulus for Junior Elite Volleyball Players? Journal of Strength and Conditioning Research 22: 509-517.

27. Claudino JG, Cronin J, Mezêncio B, McMaster DT, McGuigan M, et al. (2017) The countermovement jump to monitor neuromuscular status: A meta-analysis. J Sci Med Sport 20: 397-402.

28. Freitas VH, Nakamura FY, Miloski B, Samulski D, Bara-Filho MG (2014) Sensitivity of Physiological and Psychological Markers to Training Load Intensi- fication in Volleyball Players. J Sports Sci Med 13: 571-579.

29. Bangsbo J (2015) Performance in sports - With specific emphasis on the effect of intensified training. Scand J Med Sci Sports 25: 88-99.

30. Issurin VB (2010) New Horizons for the Methodology and Physiology of Training Periodization. Sports Med 40: 189206.
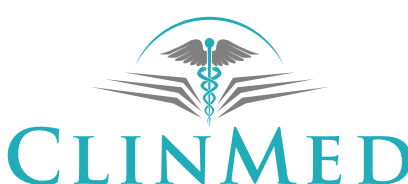

INTERNATIONAL LIBRARY 